\title{
Distilling Check-in/Check-Out into Its Core Practice Elements Through an Expert Consensus Process
}

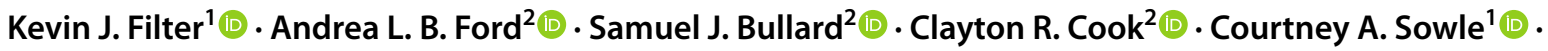 \\ LeAnne D. Johnson ${ }^{2}$ (I) Eric Kloos ${ }^{3}$. Danielle Dupuis ${ }^{2}$ (I)
}

Accepted: 6 December 2021 / Published online: 27 January 2022

(c) The Author(s), under exclusive licence to Springer Science+Business Media, LLC, part of Springer Nature 2021, corrected publication 2022

\begin{abstract}
Check-in/Check-out (CICO) is a widely implemented evidence-based program for supporting students with at-risk levels of social and emotional behavior concerns. It is comprised of several core features described in the previous literature, including practice elements, which are the specific actions that are delivered directly to students, and implementation components, which are actions that support the implementation by adults. Practice elements and implementation components are both important to implementation but have been combined and conflated in descriptions of CICO implementation. Well-defined and differentiated practice elements could provide improved clarity in communicating implementation expectations to frontline implementers as well as support future research into essential active ingredients and measures of front-line intervention fidelity. The purpose of the present study was to distill, differentiate, and operationally define the student-facing practice elements of CICO. A panel of research experts and practice experts participated in a three-round modified e-Delphi process that led to the identification and operational definition of 19 discreet practice elements organized into five domains. Results are discussed in terms in implications for future development of measures of commitment and intervention fidelity, future research into active ingredients of CICO, and in terms of how well-defined practice elements can improve communication of implementation expectations for front-line implementers of CICO such as teachers.
\end{abstract}

Keywords Implementation $\cdot$ Evidence-based program $\cdot$ Check-in/check-out $\cdot$ Expert consensus

\section{Introduction}

A significant number of students with social, emotional, and behavioral needs require intervention beyond Tier 1 universal supports (Kilgus \& Von der Embse, 2019). Given this, researchers have developed a wide range of interventions for delivery as Tier 2 targeted supports for students with social, emotional, and behavioral needs. Check-in/Checkout (CICO) is one such intervention that has numerous well-controlled studies demonstrating its effects on a wide range of outcomes, including academic engagement, disruptive behavior, and office disciplinary incidents (Hawken,

Kevin J. Filter

kevin.filter@mnsu.edu

1 Department of Psychology, Minnesota State University, 103 Armstrong Hall, Mankato, Minnesota 56001, USA

2 University of Minnesota, Twin Cities, Minneapolis, USA

3 Minnesota Department of Education, Roseville, USA
Bundock, Kladis, O'Keeffe, \& Barrett, 2014). Research has demonstrated that implementation of CICO with fidelity is key to achieving desired outcomes. Although fidelity is generally between 70 and $90 \%$ in published research studies with oversight and involvement by researchers (Hawken et al., 2015; Hawken et al., 2015), adoption and fidelity are dependent on several issues and implementation can be uneven in typical school settings (Myers \& Briere, 2010; Rodriguez, Campbell, Falcon, \& Borgmeier, 2015). One variable relevant to implementation is the delineation and conveyance of specific practice elements that represent the concrete actions that expected implementers are to perform to deliver CICO with fidelity. This allows front-line implementers, those who provide the intervention directly to students, to know what is expected of them when implementing and it facilitates measurements and feedback about front-line implementation.

Although CICO has a literature base that outlines general categories of practices (e.g., morning check-in), there are many published variations on CICO and no research has 
generated consensus from research and practice experts about the specific practice elements that are essential to CICO. Further, as with most evidence-base programs (EBPs), existing guidance for CICO combines both the adult-facing implementation components necessary to ensure that adults implement correctly (e.g., data-based decisionmaking in teams) and student-facing practice elements that are delivered directly to students by front-line implementers (e.g., providing feedback to students about their behavior). Thus, the purpose of this study was to distill, differentiate, and define the agreed upon core practice elements of CICO that front-line implementers are expected to deliver directly to students. Well-defined and differentiated practice elements can support implementation of CICO through improved communication of specific implementation behaviors expected of front-line implementers and through the establishment of psychometrically sound measures of frontline intervention fidelity and commitment.

\section{Check-in/Check-Out as a Tier 2 Intervention}

CICO was originally developed to improve the behavior of students who did not respond to Tier 1 positive behavior interventions and supports (Warberg, George, Brown, Chauran, \& Taylor-Greene, 1995; as cited by Hawken et al., 2007). It is typically comprised of several core daily features (Filter, 2019). First, students check in with a mentor in the morning to prepare for the day and receive a point card. Second, students receive regular feedback about their behavior from teachers and other adults throughout the day using the point card. Third, students check out with a mentor at the end of the day and receive any incentives that they earned based on the points earned throughout the day. Finally, the student's daily behavior performance is shared with caregivers as part of home communication.

Empirical support for CICO has been established through two decades of published studies. Multiple systematic reviews have reached the consensus that empirical evidence from single-subject designs warrant consideration for CICO as an evidence-based program (EBP) but that group design studies, while promising, are too few to draw definitive conclusions (Maggin et al., 2015; Mitchell, Adamson, \& McKenna, 2017; Wolfe et al., 2016). Early research indicated that about $70 \%$ of students who received CICO demonstrated significant reductions in problem behaviors (Filter et al., 2007; Hawken et al., 2007). These findings are consistent with prior research, with the exception that higher rates of success have been noted for students with attention-maintained behavior than for students with escape-maintained behavior (McIntosh, Campbell, Carter, \& Dickey, 2009; Wolfe et al, 2016). Several effective modifications to CICO have also been reported, including peer-mediated mentoring (Collins et al., 2016), the addition of social skills training (Ross \& Sabey, 2015), and escape-based modifications (Turtura, Anderson, \& Boyd, 2014).

The essential conditions and ingredients for successful implementation of CICO are uncertain given the range of variations of CICO. However, Campbell and Anderson (2011) provided some guidance when they conducted a brief component analysis by systematically reducing the number of regular feedback sessions with teachers. They found that one feedback session was sufficient to maintain behavior gains observed prior to reducing the frequency of feedback sessions but that the complete removal of teacher feedback sessions led to decrease in behavior performance. In terms of systematic implementation issues, Myers and Briere (2010) shared 10 lessons learned about implementing CICO in an urban middle school. Their lessons included (a) Maintaining consistency with staff, (b) Assigning responsibilities judiciously and following through, and (c) Having an organized, efficient system for collecting and synthesizing data. Hawken et al. (2015) also noted that schools with high CICO fidelity supported twice as many elementary and middle school students as schools with low CICO fidelity.

Ultimately, successful implementation of any behavioral intervention program such as CICO hinges on having precise practice elements that represent the concrete actions that the expected implementers need to perform to deliver it with fidelity (Cross \& West, 2011). When precise practice elements have been identified, then it is possible to train more precisely, assess implementer commitment more accurately, collect fidelity data to provide specific feedback to implementers, and identify and address barriers associated with specific practices to continuously improve implementation.

\section{Defining Practice Elements}

Curran (2020) differentiates the features of an intervention from the implementation strategies that are put in place to ensure implementation of the intervention. Thus, implementation behaviors associated with EBPs can be divided into the actions expected of implementers when delivering an EBP to target recipients, which we refer to us practice elements (PEs), and the actions taken by those who are supporting the expected implementers, which we label implementation components (ICs). This distinction is also noted by Dunst et al. (2013) who noted that intervention fidelity, which refers to the degree to which PEs are implemented as intended, should be differentiated from implementation fidelity, which is the degree to which ICs are implemented correctly. We define ICs as the actions taken by coaches, educators, and administrators that support and prepare staff in a school to adopt, deliver, and sustain core practice elements with fidelity. ICs are designed to support adult 
behavior change. In the case of CICO, these would include actions such as staff training, data-based decision-making, and providing feedback to front-line implementers. PEs, the focus of the present study, are the individual observable actions associated with an EBPs that expected implementers, such as teachers, paraprofessionals, and other schoolbased practitioners (e.g., counselors, school psychologists), deliver to students to promote meaningful changes in achieving desired student outcomes. PEs are designed to support student behavior change. When implementing CICO, these would include actions such as meeting with students for morning check-in, rating student behavior on point cards, and providing behavior feedback to students.

Guidance regarding CICO implementation is provided in the book, Responding to Problem Behavior in Schools, by Hawken et al. (2020). This book and its previous editions have been seminal resources in advancing research and practice on CICO. One resource included in the book is the CICO Fidelity of Implementation Measure (CICO-FIM), in which both PEs and ICs are evaluated but not delineated as core components in a measure that is completed by an implementation team in a school. An example of a PE in the CICO-FIM is "Do 90\% of students on CICO report that they receive reinforcement (e.g., verbal, tangible) for meeting daily goals?" and example of an IC in the CICOFIM is "Does the school employ a CICO coordinator whose job is to manage the CICO (10-15 h per week allocated)?" These items are combined for a full implementation score, which can be used by teams to determine the overall status of CICO in a school. Combined team-report measures such as the CICO-FIM provide very useful action-planning data. However, they are insufficient for the detailed analysis of implementation at the front-line, the level at which specific practices are received by target students. By distilling and differentiating PEs from the ICs in CICO, it will be possible to create a measure that specifically addresses intervention fidelity (i.e., the fidelity with which PEs are delivered to intended recipients; Dunst et al., 2013) of CICO that could be completed as a self-report rather than an implementation team report, thereby providing a more comprehensive picture of implementation as perceived by front-line implementers and as received by target students. These data could inform targeted action planning for training and coaching of front-line implementers.

$\mathrm{CICO}$ has been examined by several different research groups and incorporated into routine practice in a wide range of school settings, resulting in more refined perspectives of the core PEs of CICO than the original source material published well over a decade ago (Filter, 2019; Majeika, Van Camp, Wehby, Kern, Commisso, \& Gaier, 2020). The combination of the different applications of CICO in the empirical literature and increased understanding of CICO through over a decade of real-world application provides an opportunity to behaviorally define the core PEs of CICO through expert consensus, which was the focus of the present study. Although ICs are also core to implementation, the immediate goal of our project was to distill, differentiate, and define PEs to improve communication of specific expected practices for front-line implementers and establish the foundation for the future development of measures of intervention fidelity and staff commitment. When distilling PEs from an already established EBP like CICO, the inclusion of input from both researchers and practitioners is important to (a) Capture essential perspectives in the research-to-practice process that helps ensure that each PE is understandable and clear among those who are expected to deliver them with fidelity, (b) Establish concrete PE that serve as the basis for the development of psychometricallysound fidelity measures, and (c) Pinpoint directions for future research to identify which PEs are essential and how much of each one is needed (i.e., dosage) to produce changes in student behavioral outcomes. While there appears to be some shared understanding of the basic components of $\mathrm{CICO}$, there has not been a consensus-driven process undertaken with research and practice experts to identify the core PEs of CICO and establish common language that is clear and understandable to both research and practice audiences.

\section{Present Study}

The purpose of this study was to distill, differentiate, and define the core PEs of CICO in a way that people who are familiar or unfamiliar with CICO could comprehend. To accomplish these goals, we gathered multiple rounds of feedback from research and practice experts within a modified-Delphi approach. This work was intended to inform the future development and validation of CICO intervention fidelity measures and commitment measures that could be completed by front-line implementers and used by both researchers and practitioners.

To clarify, the goal of the present study was not to isolate the active ingredients of CICO (i.e., practices that are most predictive of student outcomes). That goal is best accomplished through other experimental research designs such as component analyses (e.g., Anderson \& Campbell, 2011). It is hoped, however, that the PEs distilled from the existing core features of CICO in the present study could facilitate future research into active ingredients.

The iterative rounds of feedback in the present study were guided by the following research questions:

(1) What are the PEs that both research and practice experts believe are important and core to the delivery of the CICO? 
(2) What thematic categories do the core PEs fall under for purposes of conceptual clarity?

(3) For the final set of core PEs, do research and practice experts agree they are a core feature of CICO and operationally defined in a comprehensible way?

\section{Method}

\section{Participants}

When identifying a panel of experts for the Delphi process, the goal is to ensure the individuals on the panel are highly qualified and can provide the level of expertise needed to answer the research questions. As Okoli and Pawlowski (2004, pg. 6) point out, "a Delphi study does not depend on a statistical sample that attempts to be representative of any population. It is a group decision mechanism requiring qualified experts who have deep understanding of the issues." Toward this end, our research team developed explicit criteria for identifying panelists who represented two critical perspectives on CICO: research experts and practice experts. Research experts were defined as nationally recognized individuals with an established record of (a) Publishing peer-reviewed research involving CICO and (b) Supporting school systems in implementing interventions addressing students' social emotional or behavioral needs. Practice experts were defined as individuals from one Midwestern state who had knowledge about (a) The core practice elements of CICO, (b) The methods used to evaluate CICO, (c) Data-based problem solving, and (d) Team-based action planning. In addition, the practice expert needed to have experience implementing and supporting the implementation of CICO in elementary schools for at least three years, in a variety of roles (e.g., implementer, coach, trainer, evaluator, leader), and across several contexts (e.g., age groups, schools, districts, states).

Our team then used different methods to recruit the two groups of experts to form the final panel. To identify research experts, our team generated a list of nationally recognized researchers with an established record of publishing peer-reviewed research on and supporting school systems in implementing CICO. This produced a list of five research experts, of which four agreed to participate on the panel. To identify practice experts, two of the principal investigators met with the Positive Behavior Interventions and Supports Statewide Leaderhip Team in a Midwestern state. They shared an overview of the project, our criteria for identifying practice experts, and the expectations of practice experts invited to participate. To ensure we had broad representation across the state, our team intentionally distributed the recruitment of practice experts across the three professional development regions of the state (North, Central, and South).
The three regional coordinators that were a part of the State Leadership Team then invited specific practice experts who met the criteria for participation. Regional coordinators invited up to six individuals within their region and rank them based on the fit between their experience and the qualifications with respect to our definition of a practice expert. From those nominations, a total of six individuals, two from each region, were invited and agreed to participate on the panel but one was not included in the study due to low ratings of CICO expertise.

Consistent with guidance for e-Delphi panel size (Avella, 2016; Carlsen \& Glenton, 2011; Okoli \& Pawlowski, 2004), a total of nine experts participated in our panel. Six out of the nine experts attended all three rounds; there were three experts that each missed one round. Despite our efforts to ensure full participation across the rounds, the COVID-19 pandemic impacted the ability of some of our experts to participate in a specific round.

Demographic data by individual experts are summarized in Table 1 for research experts and Table 2 for practice experts. All participants were White, not Hispanic or Latino, and had at least a Master's degree. Participants rated themselves on their effectiveness at training on, coaching on, and delivering CICO practices on a 4-point scale from not at all effective to extremely effective. Almost all participants rated themselves as very to extremely effective at training on, coaching on, and delivering CICO practices, with only one participant rating themselves as slightly effective at coaching.

\section{Procedures}

Prior to conducting this study, all procedures were reviewed by the University Institutional Review Board (IRB) which determined this study was exempt from human subjects' oversight. To answer our research questions, our team used a modified electronic Delphi (e-Delphi; Avery et al., 2005; Chou, 2002) approach to gather input from our expert participants across multiple rounds and reach consensus on essential PEs of CICO. This method involves a structured, iterative process to derive consensus among a panel of experts.

The modified e-Delphi process had three rounds that occurred over seven months (Chou, 2002; McMillan et al., 2016). Each round involved an asynchronous online approach using the Qualtrics system. The first two rounds provided the opportunity for participants to offer input about specific practice elements they believed were essential to the delivery of and outcomes associated with CICO. After each of the first two rounds, the project research team synthesized the information and made iterative refinements to the data in preparation for the subsequent round of feedback. The third round involved gathering specific ratings to obtain consensus on the final compilation of common practice elements. 


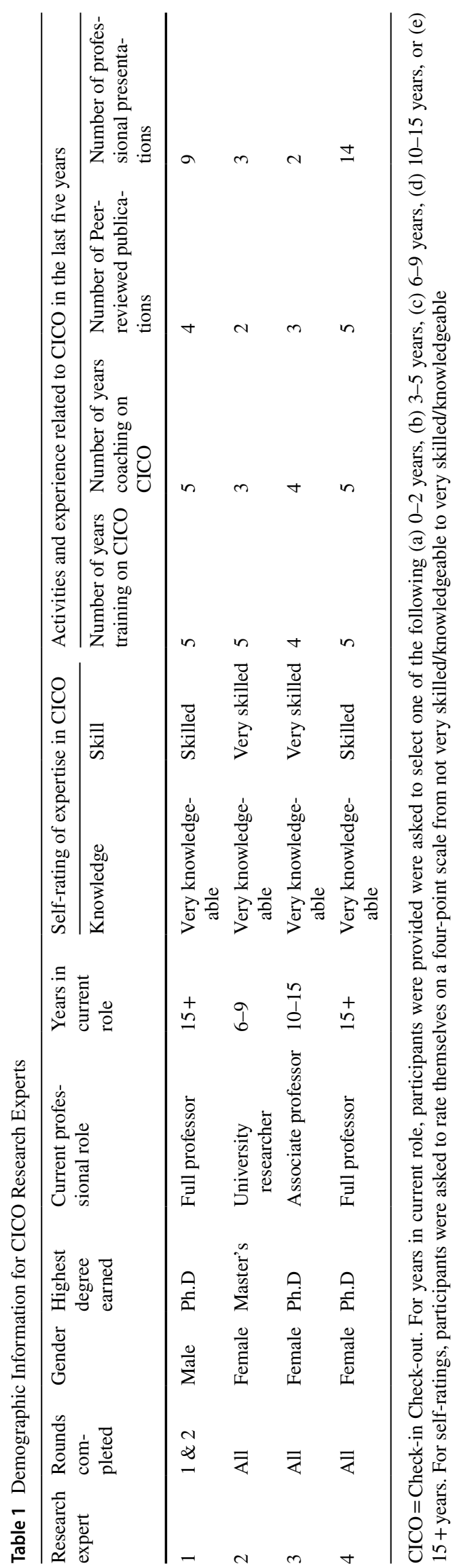

Research Question One: Generate an Exhaustive List

In advance of preparing the online surveys to distribute, our team carefully reviewed empirical literature and consulted with other researchers to refine our definitions of key terms and approaches to sharing information so that Round 1 would evoke the intended information from respondents. This work led to a table of definitions and visual conceptual model (see Fig. 1). These pieces of information were included in the online surveys and described in a brief video recorded by one of the researchers.

Our team prepared a survey for all participants that had three major parts. First, we asked participants to identify and define specific practice elements associated with CICO that represented the behaviors that expected implementers deliver to students. Second, we asked participants to provide information about their level of experience and expertise with CICO, aligning the specific questions to their designation of a research or practice expert. For example, these questions included information such as: knowledge of and skill as an implementer of CICO (i.e., both experts); duration and effectiveness at providing training, coaching, and directly implementing CICO (i.e., practice experts), and the number of professional presentations and peer-reviewed publications on CICO (i.e., research experts). Lastly, we asked them to include general demographic information (e.g., degree, gender, race, ethnicity) to allow for additional characterization of our sample. After all responses were gathered, our research team engaged in an iterative process of content analysis to identify and code themes, allowing us to consolidate redundancies and remove practices that were more indicative of implementation support (e.g., enter data in SWIS and train staff).

\section{Research Question Two: Confirm and Refine Practices, Domains, and Utility}

Following the analysis and synthesis of responses from participants in Round 1, our team identified five core practice domains composed of 16 practice elements and prepared a second survey. A summary of the domains and practice elements was reviewed by respondents, who were subsequently asked to rate (a) The importance of each practice element and domain to the CICO intervention, (b) The fit of the practice element within the domain, and (c) The relative importance of each practice element within the domain, each of which were rated on a four-point scale. We also requested that experts suggest any missing domains or PEs and offer any changes to the wording. After all responses were gathered, we summarized the data using both quantitative and qualitative methods. Specifically, we conducted descriptive quantitative analyses (e.g., measures of central tendency and 


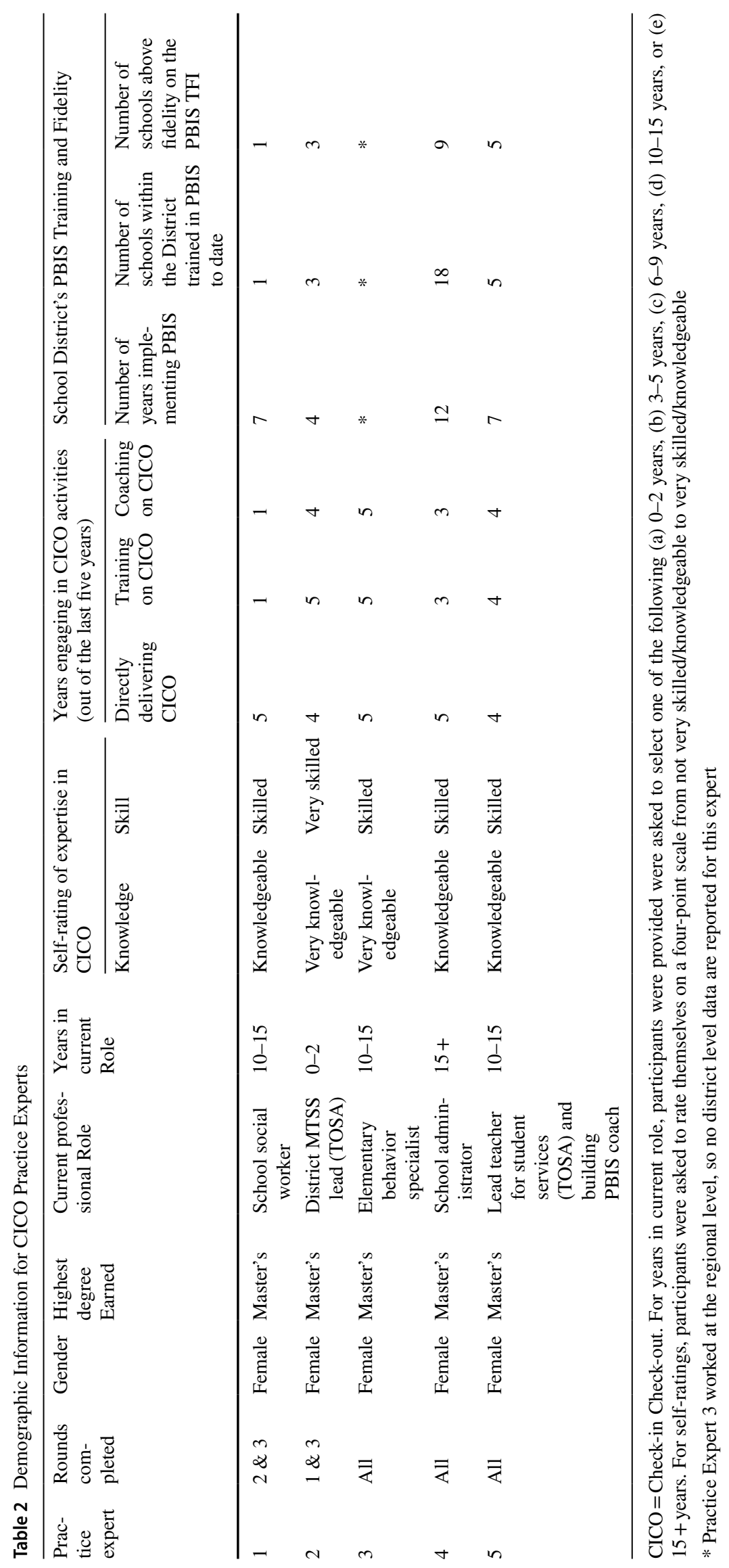


Fig. 1 Conceptualization, Identification, and Definitions of Key Terms

\begin{tabular}{lll}
\hline \multicolumn{1}{c}{ Terms } & & \\
\hline Core Features & $\begin{array}{l}\text { Inclusive of all the implementation components and practice elements } \\
\text { of a given evidence-based program that lead to changes in student } \\
\text { outcomes. }\end{array}$ & Adults and \\
students
\end{tabular}

variability) and content analyses (i.e., interpreting and coding data into themes).

\section{Research Question Three: Confirm and Refine Operationalized Descriptions}

The third round of our e-Delphi process was intended to finalize the collection of domains and practice elements of CICO following revisions made in response to feedback received from the Round 2 survey. Additionally, we hoped to assess the degree to which experts believed practitioners could understand the practice elements regardless of their prior experience with CICO. Another online survey was administered to gage these judgments. E xperts were asked to review the revised practice elements under each of the five domains (see Fig. 3 and 4) and subsequently rate whether each practice element: (a) Represented a core feature of CICO, (b) Could be understood by a practitioner familiar or experienced with CICO, and (c) Could be understood by a practitioner unfamiliar or inexperienced with CICO. All items were rated on a 4-point scale ranging from strongly disagree to strongly agree. After all responses were gathered, we summarized the data using both quantitative and qualitative methods. Specifically, we conducted descriptive quantitative analyses (e.g., measures of central tendency and variability) and content analyses (i.e., interpreting and coding data into themes).

\section{Results}

\section{Research Question One: Generate an Exhaustive List}

\section{Survey Results}

Eight of the nine experts participated in the first round of the e-Delphi process. They developed a list of 74 total practices and corresponding definitions, which can be found in the online supplementary materials. Across the experts, there was also a range in how many PEs an individual expert generated, with a minimum of 3 and a maximum of 13 PEs.

\section{Data Synthesis and Decisions Made}

Among the 74 PEs, there was significant overlap and redundancy. For example, one researcher included "Positive behavioral feedback is delivered to student approximately once every hour contingent on behavior" while a practitioner listed "Teacher offers explicit positive affirmation verbally or non-verbally whenever expected behavior is exhibited." Six members of our research team subsequently reviewed the responses and created a consolidated list of PEs. Our team refined redundancies $(n=47)$ and removed practices that were reflective of implementation supports $(n=15$; e.g., using data for decision-making), yielding a total of 12 PEs.

Our team observed that the 12 PEs shared common characteristics, suggesting they could be clustered into separate thematic categories, referred to as practice 
domains (i.e., categories under which PEs fall). We first independently created potential ways for practice elements to be organized. Then, through our own consensusbuilding process, we refined the individual responses to five practice domains. In this process, however, we identified several consolidated PEs that, particularly given our domains, represented distinct behaviors. In the end, we reached consensus on 16 PEs under five domains that were forwarded for Round 2. The column on the left of Fig. 2 displays these results.

\section{Research Question Two: Confirm and Refine Practices, Domains, and Utility}

\section{Survey Results}

Figure 3 provides the results for the Round Two survey, which was completed by a total of eight experts. Following their review of the consolidated list of domains and PEs, most experts reported that all five domains were very important to the CICO intervention. Out of the $16 \mathrm{PEs}, 75 \%$ or more of experts reported that 14 of them were very important. There was slight disagreement regarding PE \#15 (i.e., Communicate the student's progress with the family in an appropriate modality), with $62.5 \%$ of respondents indicating it was very important and $37.5 \%$ indicating it was of moderate importance. Only one practice element, PE \#6 (i.e., Collect the point sheet from the student), was reported to be moderately important rather than very important by most respondents.

Experts generally agreed that each of the PEs fit very well with their respective domains. PE \#14 (i.e., Adapt the rewards or goal if they are not working) had the greatest spread, with $25 \%$ of experts reporting that it did not at all fit with the domain Afternoon Check-Out, 12.5\% reporting it as slightly fitting, and $62.5 \%$ reporting it to fit very well.

\section{Data Synthesis and Decisions Made}

Following review of survey results from Round Two, our team found a few areas to adjust. First, there were changes regarding the wording of domains (e.g., Rating and Feedback instead of Teacher Rating and Feedback) and revisions to the wording of individual PEs to improve their comprehensibility. Expert feedback also provided three additional PEs (e.g., For each new student, discuss the goal that must be reached to earn privileges, social activities, or tangible items). The column on the right of Fig. 2 represents the changes made to the PEs and domains because of Round Two feedback.

\section{Research Question Three: Confirm and Refine Operationalized Descriptions.}

\section{Survey Results}

Figure 4 displays the results for Round 3 survey, which a total of eight experts completed. In general, experts either strongly agreed or somewhat agreed that each of the PEs was a core feature of CICO. In addition, experts strongly agreed or somewhat agreed that practitioners familiar or experienced with CICO would understand all PEs; in fact, for PEs \#1-7, 10, and 12-14, all experts strongly agreed. Experts had the most variability in their responses when asked whether practitioners unfamiliar or inexperienced with CICO could understand practice elements, with responses ranging from strongly agree to strongly disagree across most of the PEs. Despite this variability, for 15 of the 19 practice elements, $75 \%$ of the ratings still fell within strongly agree to somewhat agree, suggesting some consensus on this question.

\section{Data Synthesis and Decisions Made}

The results of the Round Three survey suggested that we had achieved consensus among our research and practice experts on the 19 PEs. With the additional information provided from the results of Round Two, the research team determined that, for this group of experts, the domains and their respective PEs identified through the e-Delphi process represent the core PEs adults involved in implementation of CICO should be expected to deliver as a part of their direct work with students.

\section{Discussion}

CICO is an effective Tier 2 intervention for students with social, emotional, and behavioral (SEB) needs, especially those who have attention-maintained behavior and performance-deficits (Hawken et al., 2014; McIntosh et al, 2009). The original research on CICO dates back to 2002 with over 40 published studies and numerous real-world applications as part of routine practice in schools (Filter, 2019). Despite the advancement of both research and practice, there has not been a process to identify core practice elements (PEs), which are the individual observable actions of student-facing front-line implementers, and develop common nomenclature for each of the PEs through input from both research and practice experts. Thus, the purpose of this study was to use a modified e-Delphi process to engage researchers and practitioners with expertise in CICO to distill CICO into core PEs as well as develop language that behaviorally defines each $\mathrm{PE}$ in a way that is likely to be easily understood by research 


\begin{tabular}{|c|c|c|}
\hline D & Pre-Teaching with the Student & Pre-teaching to Set-up the Intervention \\
\hline $\begin{array}{l}\mathbf{0} \\
\mathbf{m} \\
\mathbf{a} \\
\mathbf{i} \\
\mathbf{n}\end{array}$ & $\begin{array}{l}\text { 1. For each new student, meet with the student to review how } \\
\text { the intervention works (e.g., morning and afternoon check- } \\
\text { ins, use of the point sheet) } \\
\text { 2. For each new student, generate a behavioral goal and } \\
\text { discuss the experiences, tangible items, or privileges to } \\
\text { earn. }\end{array}$ & $\begin{array}{l}\text { 1. For each new student, meet with the student to teach how } \\
\text { the intervention works } \\
\text { 2. For each new student, explain the specific behaviors on the } \\
\text { point sheet that student is to perform. } \\
\text { 3. For each new student, discuss the goal that must be reached } \\
\text { to earn social activities, tangible items, or privileges }\end{array}$ \\
\hline D & Morning Check-in & Morning Check-in \\
\hline $\begin{array}{l}\mathbf{0} \\
\mathbf{m} \\
\mathbf{a} \\
\mathbf{i} \\
\mathbf{n} \\
2\end{array}$ & $\begin{array}{l}\text { 3. Ensure the student participates in the morning check-in } \\
\text { (that is, if needed, go find the student, request help in } \\
\text { finding the student, or set up reminders for the student) } \\
\text { 4. Positively greet student in the morning upon arrival, } \\
\text { briefly review expected behavior and behavioral goal, } \\
\text { offer words of encouragement as the student leaves } \\
\text { 5. Have point sheets available, provide a point sheet to the } \\
\text { student, and document check-in }\end{array}$ & $\begin{array}{l}\text { 4. Ensure the student participates in the morning check-in (as } \\
\text { needed, find the student, request help in finding the student, } \\
\text { or set up reminders for the student) } \\
\text { 5. Positively greet student in the morning upon arrival and } \\
\text { provide positive encouragement as they leave } \\
\text { 6. Have point sheets available, provide a point sheet to the } \\
\text { student, and document check-in } \\
\text { 7. Briefly review expected behavior, goal to be reached, and } \\
\text { materials needed for the day }\end{array}$ \\
\hline $\mathbf{D}$ & Teacher Rating and Feedback & Rating and Feedback \\
\hline $\begin{array}{l}\mathbf{0} \\
\mathbf{m} \\
\mathbf{a} \\
\mathbf{i} \\
\mathrm{n} \\
\mathbf{3}\end{array}$ & $\begin{array}{l}\text { 6. Collect the point sheet from the student } \\
\text { 7. Rate student behavior on point sheet at the agreed upon } \\
\text { frequencies (intervals of time) for the time you are with } \\
\text { the student } \\
\text { 8. Provide positive verbal feedback to the student when } \\
\text { expectations have been met } \\
\text { 9. Provide constructive feedback to the student when } \\
\text { expectations have not been met }\end{array}$ & $\begin{array}{l}\text { 8. Collect the point sheet from the student } \\
\text { 9. Rate student behavior on the point sheet at the agreed-upon } \\
\text { frequencies (intervals of time) for the time you are with the } \\
\text { student } \\
\text { 10. Provide positive verbal feedback to the student when } \\
\text { expectations have been met } \\
\text { 11. Provide constructive feedback to the student when } \\
\text { expectations have not been met }\end{array}$ \\
\hline D & Afternoon Check-Out & Afternoon Check-Out \\
\hline $\begin{array}{l}\mathbf{0} \\
\mathbf{m} \\
\mathbf{a} \\
\mathbf{i} \\
\mathrm{n} \\
4\end{array}$ & $\begin{array}{l}\text { 10. Ensure the student participates in the afternoon check-outs } \\
\text { (if needed, go find the student, request help in finding the } \\
\text { student, or set up reminders for the student) } \\
\text { 11. Positively greet the student upon arrival, ask for the point } \\
\text { sheet, and review the point sheet with the student } \\
\text { 12. Provide positive or constructive verbal feedback to the } \\
\text { student based on performance } \\
\text { 13. Deliver the agreed-upon reward if the student met } \\
\text { established goal } \\
\text { 14. Adapt the rewards or goal if they are not working (for } \\
\text { example, adjust rewards if the student is not motivated by } \\
\text { them or adjust the goal if it is too high or low) }\end{array}$ & $\begin{array}{l}\text { 12. Ensure the student participates in the afternoon check-outs } \\
\text { (as needed, find the student, request help in finding the } \\
\text { student, or set up reminders for the student) } \\
\text { 13. Positively greet the student upon arrival and provide } \\
\text { encouragement as leave for the day } \\
\text { 14. Ask for the point sheet and review the point sheet with the } \\
\text { student } \\
\text { 15. Provide positive or constructive verbal feedback to the } \\
\text { student based on performance } \\
\text { 16. Deliver the agreed-upon social activities, tangible items, or } \\
\text { privileges if the student met established goal } \\
\text { 17. If a student's goal is not being met on a daily basis, discuss } \\
\text { with the student what is working or not working from the } \\
\text { student's perspective and make small adjustments as needed }\end{array}$ \\
\hline $\mathbf{D}$ & Home Communication & Home Communication \\
\hline $\begin{array}{l}\mathbf{0} \\
\mathbf{m} \\
\mathbf{a} \\
\mathbf{i} \\
\mathbf{n} \\
\mathbf{5}\end{array}$ & $\begin{array}{l}\text { 15. Communicate the student's progress with the family in an } \\
\text { appropriate modality (i.e., email, text, phone, or hard } \\
\text { copy) } \\
\text { 16. For each new student, communicate to caregiver how to } \\
\text { review point sheet results and deliver feedback to their } \\
\text { child by praising them for meeting goal or reviewing how } \\
\text { to have a better day tomorrow if the goal was unmet }\end{array}$ & $\begin{array}{l}\text { 18. Communicate the student's progress on a daily or weekly } \\
\text { basis with the family using an appropriate modality (for } \\
\text { example, email, text, phone, or hard copy) } \\
\text { 19. When implementing with a new student, explain program to } \\
\text { caregiver, including how to review point sheet results and } \\
\text { deliver positive and constructive feedback to their child }\end{array}$ \\
\hline
\end{tabular}

Fig. 2 Domains and Practice Elements Generated Following Round One and Round Two 


\begin{tabular}{|c|c|c|c|c|c|c|c|c|}
\hline & \multicolumn{4}{|c|}{ How well does this practice $F T$ within this domain? } & \multicolumn{4}{|c|}{ How IMPORTANT is this practice within this domain? } \\
\hline & Very Well & Moderately Well & Slighty Fitting & $\begin{array}{c}\text { Not at All } \\
\text { Fitting }\end{array}$ & Very Important & $\begin{array}{c}\text { Moderately } \\
\text { Important }\end{array}$ & $\begin{array}{c}\text { Slightly } \\
\text { Important }\end{array}$ & $\begin{array}{l}\text { Not at All } \\
\text { Important }\end{array}$ \\
\hline \multicolumn{9}{|l|}{ Domain \#1: Pre-Teaching with the Student } \\
\hline $\begin{array}{l}\text { 1. For each new student, meet with the student to review how the intervention works (e.g, morning and afternoon check-ins, } \\
\text { use of the point shcer) }\end{array}$ & $87.5 \%$ & $0 \%$ & $12.5 \%$ & $0 \%$ & $100 \%$ & $0 \%$ & $0 \%$ & $0 \%$ \\
\hline 2. For cach new student, generate a behavioral goal and discuss the experiences, tangible items, or privileges to carn. & $75 \%$ & $12.5 \%$ & $0 \%$ & $12.5 \%$ & $87.5 \%$ & $12.5 \%$ & $0 \%$ & $0 \%$ \\
\hline \multicolumn{9}{|l|}{ Domain \#2: Morning Check-in } \\
\hline $\begin{array}{l}\text { 3. Ensure the student participates in the morning check-in (that is, if needed, go find the sudent, request help in finding the } \\
\text { student, or set up reminders for hhe student) }\end{array}$ & $87.5 \%$ & $12.5 \%$ & $0 \%$ & $0 \%$ & $100 \%$ & $0 \%$ & $0 \%$ & $0 \%$ \\
\hline $\begin{array}{l}\text { 4. Positively greet student in the morning upon arrival, briefly review expected behavior and behavioral goal, offer words of } \\
\text { encouragement as the sudent leaves }\end{array}$ & $100 \%$ & $\%$ & $0 \%$ & $0 \%$ & $100 \%$ & \% & $0 \%$ & $0 \%$ \\
\hline 5. Have point sheets available, provide a point sheet to the student, and document check-in & $87.5 \%$ & $0 \%$ & $12.5 \%$ & $0 \%$ & $87.5 \%$ & $0 \%$ & $12.5 \%$ & $0 \%$ \\
\hline \multicolumn{9}{|l|}{ Domain \#3: Teacher Rating and Feedback } \\
\hline 6. Collect the point sheet from the student & $75 \%$ & $25 \%$ & $0 \%$ & $0 \%$ & $37.5 \%$ & $62.5 \%$ & $0 \%$ & $0 \%$ \\
\hline 7. Rate student behavior on point sheet at the agreed upon frequencies (intervals of time) for the time you are with the student & $100 \%$ & $0 \%$ & $0 \%$ & $0 \%$ & $87.5 \%$ & $12.5 \%$ & $0 \%$ & $0 \%$ \\
\hline 8. Provide positive verbal fecdback to the student when expectations have been met & $100 \%$ & $0 \%$ & $0 \%$ & $0 \%$ & $100 \%$ & $0 \%$ & $0 \%$ & $0 \%$ \\
\hline 9. Provide constructive fecdback to the student when expectations have not been met & $87.5 \%$ & $0 \%$ & $12.5 \%$ & $0 \%$ & $87.5 \%$ & $0 \%$ & $12.5 \%$ & $0 \%$ \\
\hline \multicolumn{9}{|l|}{ Domain \#4: Afternoon Check-Out } \\
\hline $\begin{array}{l}\text { 10. Ensure the student participates in the afternoon check-outs (that is, if needed, go find the student, request help in finding } \\
\text { the student, or set up reminders for the student) }\end{array}$ & $100 \%$ & $0 \%$ & $0 \%$ & $0 \%$ & $100 \%$ & $0 \%$ & $0 \%$ & $0 \%$ \\
\hline 11. Positively greet the student upon arrival, ask for the point sheet, and review the point sheet wilh the student & $100 \%$ & $0 \%$ & $0 \%$ & $0 \%$ & $100 \%$ & $\%$ & $0 \%$ & $0 \%$ \\
\hline 12. Provide positive or constructive verbal feedback to the student based on performance & $100 \%$ & $0 \%$ & $0 \%$ & $0 \%$ & $100 \%$ & $0 \%$ & $0 \%$ & $0 \%$ \\
\hline 13. Deliver the agreed-upon reward if the student met established goal & $75 \%$ & $12.5 \%$ & $12.5 \%$ & $0 \%$ & $100 \%$ & $0 \%$ & $0 \%$ & $0 \%$ \\
\hline $\begin{array}{l}\text { 14. Adapt the rewards or goal if hhey are not working (for example, adjust rewards if the student is not motivated by them or } \\
\text { adjust the goal if it is too high or low) }\end{array}$ & $62.5 \%$ & $0 \%$ & $12.5 \%$ & $25 \%$ & $75 \%$ & $12.5 \%$ & $0 \%$ & $12.5 \%$ \\
\hline \multicolumn{9}{|l|}{ Domain \#5: Home Communication } \\
\hline 15. Communicate the student's progress with the family in an appropriate modality (i.e., email, text, phone, or hard copy) & $100 \%$ & $0 \%$ & $0 \%$ & $0 \%$ & $62.5 \%$ & $37.5 \%$ & $0 \%$ & $0 \%$ \\
\hline $\begin{array}{l}\text { 16. For ceach new student, communicate to carceiver how to review point shect results and deliver fecedback to their child by } \\
\text { prasising them for mecting goal or reviewing how to have a better day tomorrow if the gaal was unmet }\end{array}$ & $100 \%$ & $0 \%$ & $\%$ & \%\% & $75 \%$ & $25 \%$ & $0 \%$ & $0 \%$ \\
\hline
\end{tabular}

Fig. 3 Round 2 Results for the Perceived Fit, Importance, and Variability of Each Practice Element Note Each bar represents the percentage of expert endorsement of the rating

and practice audiences alike. These distilled and defined CICO PEs could improve communication of implementation expectations to front-line implementers and inform the development of measures of PE fidelity and commitment.

Regarding the first research question, we determined through an expert consensus process that 19 PEs were believed to be core to the implementation of CICO (see the Round 2 Results column of Fig. 2). The 19 PEs were refined from an original list of 74 suggestions obtained from experts in the first round of the study. These suggestions were reduced to 19 after eliminating redundant suggestions, eliminating suggestions that did not meet the criteria for PEs due mostly to being ICs, refining wording through expert and research team suggestions, and adding several before the third confirmatory round of data collection.

The modified e-Delphi process culminated in 5 domains of PEs, which addressed the second research question about thematic categories of CICO PEs. The five domains were (a) Pre-teaching to set-up the intervention, (b) Morning checkin, (c) Rating and feedback, (d) Afternoon check-out, and (e)
Home communication. These domains align closely with the features of CICO that have been described throughout the literature on CICO and typically include check-in, feedback from teachers, check-out, communication with parents, and data-based decision-making (Crone et al., 2020; Filter, 2019; Hawken et al., 2007). However, these features as reported in the previous literature have included both ICs and PEs and have not been presented as an organized system of PEs embedded within domains. Also, the first domain from the present study, pre-teaching to set-up the intervention, is not typically included in lists of core CICO components. This domain emerged from the present study because, although it is not a daily implementation feature like the PEs in the other four domains, it is a set of practices that are student-facing and required for implementation of $\mathrm{CICO}$, thus meeting the criteria for PEs.

Regarding the third research question, results indicated strong expert consensus on the final set of 19 PEs organized into five domains. All the experts agreed that all 19 PEs were a core feature of $\mathrm{CICO}$ with the majority indicating 


\begin{tabular}{|c|c|c|c|c|c|c|c|c|}
\hline & \multicolumn{2}{|c|}{$\begin{array}{l}\text { To what extent does the } \\
\text { practice element represent a } \\
\text { CORE FEATURE of CICO? }\end{array}$} & \multicolumn{2}{|c|}{$\begin{array}{l}\text { To what extent could each of } \\
\text { the practice element be } \\
\text { understood by a practitioner } \\
\text { FAMILIAR or } \\
\text { EXPERIENCED with } \\
\text { CICO? }\end{array}$} & \multicolumn{4}{|c|}{$\begin{array}{l}\text { To what extent could each of the practice element be } \\
\text { understood by a practitioner UNFAMILIAR or } \\
\text { INEXPERIENCED with CICO? }\end{array}$} \\
\hline & $\begin{array}{c}\text { Strongly } \\
\text { Agree }\end{array}$ & $\begin{array}{c}\text { Somewhat } \\
\text { Agree }\end{array}$ & $\begin{array}{c}\text { Strongly } \\
\text { Agree }\end{array}$ & $\begin{array}{c}\text { Somewhat } \\
\text { Agree }\end{array}$ & $\begin{array}{c}\text { Strongly } \\
\text { Agree }\end{array}$ & $\begin{array}{c}\text { Somewhat } \\
\text { Agrec }\end{array}$ & $\begin{array}{c}\text { Somewhat } \\
\text { Disagree }\end{array}$ & $\begin{array}{l}\text { Strongly } \\
\text { Disagree }\end{array}$ \\
\hline \multicolumn{9}{|l|}{ Domain \#1: Pre-Teaching to Set-up the Intervention } \\
\hline $\begin{array}{l}\text { 1. For each new student, meet with the student to teach how the intervention works (for example, check in routines, overview } \\
\text { of point sheet, role play receipt of corrective feedback, delivery of reward) (e.g., morning and afternoon check-ins, use of the } \\
\text { point sheet) }\end{array}$ & $100 \%$ & $0 \%$ & $100 \%$ & $0 \%$ & $37.5 \%$ & $37.5 \%$ & $25 \%$ & $0 \%$ \\
\hline 2. For each new student, explain the specific behaviors on the point sheet that student is to perform. & $87.5 \%$ & $12.5 \%$ & $100 \%$ & $0 \%$ & $37.5 \%$ & $37.5 \%$ & $25 \%$ & $0 \%$ \\
\hline $\begin{array}{l}\text { 3. For each new student, discuss the goal (for example, } 70 \% \text { of possible points) that must be reached to earn social activities, } \\
\text { tangible items, or privileges. }\end{array}$ & $100 \%$ & $0 \%$ & $100 \%$ & $0 \%$ & $50 \%$ & $25 \%$ & $25 \%$ & $0 \%$ \\
\hline \multicolumn{9}{|l|}{ Domain \#2: Morning Check-in } \\
\hline $\begin{array}{l}\text { 4. Ensure the student participates in the morning check-in (as needed, find the student, request help in finding the student, or } \\
\text { set up reminders for the student) }\end{array}$ & $100 \%$ & $0 \%$ & $100 \%$ & $0 \%$ & $50 \%$ & $25 \%$ & & $12.5 \%$ \\
\hline 5. Positively greet student in the morning upon arrival and provide positive encouragement as they leave & $100 \%$ & $0 \%$ & $100 \%$ & $0 \%$ & $62.5 \%$ & $12.5 \%$ & $25 \%$ & $0 \%$ \\
\hline 6. Have point sheets available, provide a point sheet to the student, and document check-in & $100 \%$ & $0 \%$ & $100 \%$ & $0 \%$ & $50 \%$ & $12.5 \%$ & $37.5 \%$ & $0 \%$ \\
\hline 7. Briefly review expected behavior, goal to be reached, and materials needed for the day & $100 \%$ & $0 \%$ & $100 \%$ & $0 \%$ & $25.0 \%$ & $37.5 \%$ & $25.0 \%$ & $12.5 \%$ \\
\hline \multicolumn{9}{|l|}{ Domain \#3: Rating and Feedback } \\
\hline 8. Collect the point sheet from the student & $62.5 \%$ & $37.5 \%$ & $87.5 \%$ & $12.5 \%$ & $50 \%$ & $37.5 \%$ & & $0 \%$ \\
\hline $\begin{array}{l}\text { 9. Rate student behavior on the point sheet at the agreed-upon frequencies (intervals of time) for the time you are with the } \\
\text { student }\end{array}$ & $100 \%$ & $0 \%$ & $87.5 \%$ & $12.5 \%$ & $25 \%$ & $50 \%$ & & $12.5 \%$ \\
\hline 10. Provide positive verbal feedback to the student when expectations have been met & $100 \%$ & $0 \%$ & $100 \%$ & $0 \%$ & $62.5 \%$ & $25 \%$ & $12.5 \%$ & $0 \%$ \\
\hline 11. Provide constructive feedback to the student when expectations have not been met & $100 \%$ & $0 \%$ & $87.5 \%$ & $12.5 \%$ & $25 \%$ & $37.5 \%$ & $25 \%$ & $12.5 \%$ \\
\hline \multicolumn{9}{|l|}{ Domain \#4: Afternoon Check-Out } \\
\hline $\begin{array}{l}\text { 12. Ensure the student participates in the afternoon check-outs (as needed, find the student, request help in finding the student, } \\
\text { or set up reminders for the student) }\end{array}$ & $100 \%$ & $0 \%$ & $100 \%$ & $0 \%$ & $50 \%$ & $50 \%$ & $0 \%$ & $0 \%$ \\
\hline 13. Positively greet the student upon arrival and provide encouragement as leave for the day & $100 \%$ & $0 \%$ & $100 \%$ & $0 \%$ & $62.5 \%$ & $37.5 \%$ & $0 \%$ & $0 \%$ \\
\hline 14. Ask for the point sheet and review the point sheet with the student & $100 \%$ & $0 \%$ & $100 \%$ & $0 \%$ & $62.5 \%$ & $25 \%$ & $12.5 \%$ & $0 \%$ \\
\hline 15. Provide positive or constructive verbal feedback to the student based on performance & $100 \%$ & $0 \%$ & $87.5 \%$ & $12.5 \%$ & $62.5 \%$ & $12.5 \%$ & $25 \%$ & $0 \%$ \\
\hline 16. Deliver the agreed-upon social activities, tangible items, or privileges if the student met established goal & $87.5 \%$ & $12.5 \%$ & $87.5 \%$ & $12.5 \%$ & $25 \%$ & $62.5 \%$ & $12.5 \%$ & $0 \%$ \\
\hline $\begin{array}{l}\text { 17. If the student's goal is not being met on a daily basis, discuss with the student what is working or not working from the } \\
\text { student's perspective and make small adjustments as needed }\end{array}$ & $87.5 \%$ & $12.5 \%$ & $75 \%$ & $25 \%$ & $25 \%$ & $37.5 \%$ & 12.5 & $25 \%$ \\
\hline \multicolumn{9}{|l|}{ Domain \#5: Home Communication } \\
\hline $\begin{array}{l}\text { 18. Communicate the student's progress on a daily or weekly basis with the family using an appropriate modality (for } \\
\text { example, email, text, phone, or hard copy) }\end{array}$ & $87.5 \%$ & $12.5 \%$ & $87.5 \%$ & $12.5 \%$ & $37.5 \%$ & $37.5 \%$ & $25 \%$ & $0 \%$ \\
\hline $\begin{array}{l}\text { 19. When implementing with a new student, explain program to caregiver, including how to review point sheet results and } \\
\text { deliver positive and constructive feedback to their child }\end{array}$ & $87.5 \%$ & $12.5 \%$ & $87.5 \%$ & 12.5 & $37.5 \%$ & $37.5 \%$ & $12.5 \%$ & $12.5 \%$ \\
\hline
\end{tabular}

Fig. 4 Round 3 Results for Whether the Practice Element is a Core Feature of CICO and Could be Understood by Varying Degrees of Familiarity Note Bars represent percentages of expert endorsement of a rating

"strongly agree" for all PEs and only one or two indicating "somewhat agree" for six of the 19 PEs, which was on the positive/confirming end of the response option range. In terms of alignment of PEs within domains, expert consensus was demonstrated with all PEs receiving endorsements of fitting "very well" within the domain from $62.5 \%$ and $100 \%$ of respondents. Also in regard to the third research question, experts indicated that the PEs were described in a way that could be understood by experienced CICO implementers. The experts were not as confident, however, that the PEs would be understood well by individuals unfamiliar or inexperienced with CICO. This is not an unexpected finding and highlights the importance of providing training with these PEs before holding educators responsible for CICO PE implementation or any self-evaluation related to implementation of the CICO PEs.

One issue that emerged from the present study but has not yet been addressed is the issue of which educators are responsible for implementing specific CICO PEs and/or domains of CICO PEs. There seem to be two distinct roles in the school-based implementation of CICO PEs: educators who serve as coordinators/facilitators and educators who serve as regular providers of feedback to students throughout the day. Although not confirmed in the present study, it is likely that the only domain that applies to most educators in a school is rating and feedback, which includes rating student behavior on point sheets and providing verbal feedback at regular, agree-upon intervals. These PEs should be 
implemented by any educator who provides regular educational services directly to students receiving $\mathrm{CICO}$ as an intervention such as classroom teachers, each of whom may be responsible for implementing this domain of PEs for multiple students in their classrooms. The other four domains of CICO PEs likely apply only to educators who serve as coordinators or facilitators that meet with students receiving CICO to check them in, check them out, and manage their involvement in CICO. The interaction of role and relevant PE domains is important to consider when using the PEs as guidance for front-line implementers and fidelity evaluation.

\section{Limitations}

The results regarding expert consensus on CICO PEs should be considered in the context of limitations in the present study. First, although the research experts and practice experts each met criteria for inclusion as experts regarding CICO, they represented a demographically homogenous group with all being White non-Hispanic and mostly women. Also, although research experts were selected from a broad national sample, all practice experts were from one state in the Midwest. The Delphi method used in this study focuses on expertise of panelists rather than demographic representation (Okoli \& Pawlawksi, 2004), so expertise was well-represented in accordance with the conventions of Delphi method. Recruitment focused on one state to leverage the existing management, coaching, and training infrastructure in the state which facilitated the identification of practitioners with expertise in CICO. It is possible that different PEs could have emerged from a more diverse sample of experts, but the specific impacts are unknown. Finally, the purpose of this work was not to empirically test which PEs are essential. That pursuit would require more experimentally rigorous designs such as systematic withdrawals in a component analysis such as those used by Anderson and Campbell (2011). Instead, this study provides findings that could enable such work in the future.

\section{Relevance to Implementation and Future Research}

There are several ways in which these newly identified core CICO PEs could contribute to future research and supports for CICO implementation. One potential value of well-defined PEs is their relevance to the development of a psychometrically sound front-line intervention fidelity measure that could be used in both practice and research applications. A CICO intervention fidelity measure for front-line implementers could evaluate the degree to which CICO is implemented across the full range of core PEs. Also, CICO PEs are relevant to the development of a psychometrically sound measure of staff commitment to implement CICO. Filter and Brown (2019) point out the importance of differentiating the specific implementation behaviors relevant to an EBP when measuring staff commitment because commitment to a practice is better understood in terms of the multiple discreet practices included in the EBP rather than the practice as a unitary whole. PE differentiation also allows for more targeted use of the results of a survey of staff commitment. If schools had access to data about staff commitment to implement CICO that are differentiated across specific PEs, then they could use those data to drive decisions about readiness to implement all PEs and areas of potential specific concern for sustained implementation. Finally, the well-defined core CICO PEs derived from the present study can be used to develop staff professional development that is organized around the separate PEs, the effectiveness of which could be evaluated using CICO fidelity measures developed based on the PEs and measures of student outcomes.

Another direction for future research relates to importance of each PE to achieving positive student outcomes. The present study identified a wide range of PEs that represent core expected implementation behaviors for frontline implementers of CICO. However, it is likely that these PEs vary in terms of their specific contributions to positive student outcomes. Future research will need to identify which of these PEs are essential and which fall in the range of the adaptable periphery. Ideally this would be evaluated with a component analysis design in which each $\mathrm{PE}$ is systematically varied to evaluate its impact on student outcomes. This issue is also relevant to the practical applications of the PEs identified in this study as schools often adapt EBPs such as CICO to accommodate the needs, systems, and resources of the school. Although the 19 PEs represent current consensus among experts, it is unclear which or how many of these PEs schools must implement to achieve positive student outcomes. Therefore, it is recommended that all 19 PEs be implemented with the caveat that school-based decisions should be informed by future research about the PEs and local evidence of student outcomes.

Although PEs were the focus of the present study, ICs are also important ingredients in effective implementation. Therefore, the procedures from the present study would be relevant to the distillation of ICs of CICO in future research. The modified Delphi process was effective in distilling PEs and could be applied when defining ICs of CICO, thereby providing a comprehensive view of implementation. 


\section{Conclusion}

CICO is a well-established and effective intervention for students with at-risk behavior needs in schools (Maggin et al., 2015; Mitchell, Adamson, \& McKenna, 2017; Wolfe et al., 2016). It has, however, been implemented with many variations (Filter, 2019) and guidance on core implementation features has combined front-line implementer behaviors (PEs) with adult-facing implementation supports (ICs) necessary for successful implementation (Hawken et al., 2020). The present study differentiated the 19 PEs of CICO by leveraging the expertise of researchers and practitioners under the assumption that having precise and well-defined PEs that represent the concrete actions that the expected implementers need to perform are essential to delivering CICO with fidelity (Cross \& West, 2011). Well-defined PEs can also standardize descriptions of the standard practice of $\mathrm{CICO}$ and facilitate the future development of measures of front-line intervention fidelity and commitment to implement CICO.

Supplementary Information The online version contains supplementary material available at https://doi.org/10.1007/s12310-021-09495-x.

Authors' Contributions Authorship order was organized to reflect the contribution of each author to the study and to the writing of the manuscript and agreed upon by all authors.

Funding This work was supported by the National Center for Education Research, Institute of Education Sciences (Grant \#R305A190182). The statements do not necessarily reflect the views of our funders and all errors and omissions are our own.

Data Availability Since the study did not include any inferential data, it is presumed that the dataset is of limited public interest for purposes such as secondary analysis. Data are not publicly posted but the authors will gladly share if requested.

\section{Declarations}

Conflicts of Interest The authors declare that they have no conflict of interest.

Ethics Approval This study was reviewed prior to being conducted by the Institutional Review Board of the University of Minnesota and was determined to be exempt. The Institutional Review Board of Minnesota State University, Mankato concurs with this status.

Code Availability Data were collected in Qualtrics online survey software and have been reported in terms of descriptive statistics, primarily frequency counts. No coding occurred other than the simple organization into the two types of participants, research experts and practice experts. Thus, the only available data are the raw data set and the tables and figures we have created. We are, however, happy to share these upon request.

Consent to Participate All participants consented to participate in the study by completing a consent form on the first page of the Qualtrics questionnaire before being included in the study.
Consent for Publication All participants were informed of the nature of the study and the intent of the authors to disseminate the findings prior to providing consent to participate.

\section{References}

Avella, R. J. (2016). Delphi panels: Research design, procedures, advantages, and challenges. International Journal of Doctoral Studies, 11, 305-321. https://doi.org/10.28945/3561

Avery, A., Savelyich, B., Sheikh, A., Cantrill, J., Morris, C., Fernando, B., \& Teasdale, S. (2005). Identifying and establishing consensus on the most important safety features of GP computer systems: e-Delphi study. Journal of Innovation in Health Informatics, 13(1), 3-11. https://doi.org/10.14236/jhi.v13i1.575

Campbell, A., \& Anderson, C. M. (2011). Check-in/check-out: A systematic evaluation and component analysis. Journal of Applied Behavior Analysis, 44(2), 315-326. https://doi.org/10.1901/jaba. 2011.44-315

Carlsen, B., \& Glenton, C. (2011). What about N? A methodological study of sample-size reporting in focus group studies. BMC Medical Research Methodology. https://doi.org/10.1186/ 1471-2288-11-26

Chou, C. (2002). Developing the e-Delphi system: A web-based forecasting tool for educational research. British Journal of Educational Technology, 33(2), 233-236.

Collins, T. A., Gresham, F. M., \& Dart, E. H. (2016). The effects of peer-mediated check-in/check-out on the social skills of socially neglected students. Behavior Modification, 40(4), 568-588. https://doi.org/10.1177/0145445516643066

Cross, W., \& West, J. (2011). Examining implementer fidelity: Conceptualizing and measuring adherence and competence. Journal of Children's Services, 6(1), 18-33. https://doi.org/10.5042/jcs. 2011.0123

Curran, G. M. (2020). Implementation science made too simple: A teaching tool. Implementation Science Communications, 1(27), 1-3. https://doi.org/10.1186/s43058-020-00001-z

Dunst, C. J., Trivette, C. M., \& Raab, M. (2013). An implementation science framework for conceptualizing and operationalizing fidelity in early childhood intervention studies. Journal of Early Intervention, 35(2), 85-101. https://doi.org/10.1177/1053815113 502235

Filter, K. J. (2019). Check-In/Check-Out. Handbook of Behavioral Interventions in Schools. https://doi.org/10.1093/med-psych/ 9780190843229.003.0017

Filter, K. J., McKenna, M. K., Benedict, E. A., Horner, R. H., Todd, A., \& Watson, J. (2007). Check in/ check out: A post-hoc evaluation of an efficient, secondary-level targeted intervention for reducing problem behaviors in schools. Education and Treatment of Children, 30(1), 69-84. https://doi.org/10.1353/etc.2007.0000

Hawken, L. S., Bundock, K., Barrett, C. A., Eber, L., Breen, K., \& Phillips, D. (2015). Large-scale implementation of check-in, checkout. Canadian Journal of School Psychology, 30(4), 304-319. https://doi.org/10.1177/0829573515601005

Hawken, L. S., Bundock, K., Kladis, K., O’Keeffe, B., \& Barrett, C. A. (2014). Systematic review of the check-in, check-out intervention for students at risk for emotional and behavioral disorders. Education and Treatment of Children, 37(4), 635-658. https://doi.org/ 10.1353/etc. 2014.0030

Hawken, L. S., Crone, D. A., Bundock, K., \& Horner, R. H. (2020). Responding to problem behavior in schools: The Check-In, CheckOut Intervention (3rd ed.). Guilford Press.

Hawken, L. S., MacLeod, K., \& Rawlings, L. (2007). Effects of the behavior education program (BEP) on office discipline referrals 
of elementary school students. Journal of Positive Behavior Interventions, 9(2), 94-101. https://doi.org/10.1177/109830070700900 20601

Kilgus, S. P., \& von der Embse, N. P. (2019). General model of service delivery for school-based interventions. In E. Dart \& K. Radley (Eds.), Handbook of Behavioral Interventions in Schools: MultiTiered Systems of Support (pp. 106-133). Oxford University Press.

Maggin, D. M., Zurheide, J., Pickett, K. C., \& Baillie, S. J. (2015). A systematic evidence review of the check-in/check-out program for reducing student challenging behaviors. Journal of Positive Behavior Interventions, 17(4), 197-208. https://doi.org/10.1177/ 1098300715573630

Majeika, C. E., Van Camp, A. M., Wehby, J. H., Kern, L., Commisso, C. E., \& Gaier, K. (2020). An evaluation of adaptations made to check-in check-out. Journal of Positive Behavior Interventions, 22(1), 25-37. https://doi.org/10.1177/1098300719860131

McIntosh, K., Campbell, A. L., Carter, D. R., \& Rossetto Dickey, C. (2009). Differential effects of a tier two behavior intervention based on function of problem behavior. Journal of Positive Behavior Interventions, 11(2), 82-93. https://doi.org/10.1177/ 1098300708319127

McMillan, S. S., King, M., \& Tully, M. P. (2016). How to use the nominal group and Delphi techniques. International Journal of Clinical Pharmacy. https://doi.org/10.1007/s11096-016-0257-x

Mitchell, B. S., Adamson, R., \& McKenna, J. W. (2017). Curbing our enthusiasm: An analysis of the check-in/check-out literature using the council for exceptional children's evidence-based practice standards. Behavior Modification, 41(3), 343-367. https://doi. org/10.1177/0145445516675273

Myers, D. M., \& Briere, D. E., III. (2010). Lessons learned from implementing a check-in/check-out behavioral program in an urban middle school. Beyond Behavior, 19(2), 21-27.
Okoli, C., \& Pawlowski, S. D. (2004). The Delphi method as a research tool: An example, design considerations and applications. Information \& Management, 42(1), 15-29. https://doi.org/10.1016/j. im.2003.11.002

Rodriguez, B. J., Campbell, A., Fairbanks Falcon, S., \& Borgmeier, C. (2015). Examination of critical features and lessons learned for implementation of a tier 2 intervention system for social behavior. Journal of Educational and Psychological Consultation, 25(2-3), 224-251. https://doi.org/10.1080/10474412.2014.929953

Ross, S. W., \& Sabey, C. V. (2015). Check-In Check-Out + Social Skills: Enhancing the Effects of Check-In Check-Out for Students With Social Skill Deficits. Remedial and Special Education, 36(4), 246-257. https://doi.org/10.1177/0741932514553125

Turtura, J. E., Anderson, C. M., \& Boyd, R. J. (2014). Addressing task avoidance in middle school students. Journal of Positive Behavior Interventions, 16(3), 159-167. https://doi.org/10.1177/10983 00713484063

Warberg, A., George, N., Brown, D., Chauran, K., \& Taylor-Greene, S. (1995). Behavior Education Plan Handbook. Fern Ridge Middle School.

Wolfe, K., Pyle, D., Charlton, C. T., Sabey, C. V., Lund, E. M., \& Ross, S. W. (2016). A systematic review of the empirical support for check-in check-out. Journal of Positive Behavior Interventions, 18(2), 74-88. https://doi.org/10.1177/1098300715595957

Publisher's Note Springer Nature remains neutral with regard to jurisdictional claims in published maps and institutional affiliations. 